\title{
What can we really say about skeletal part representation, MNI and funerary ritual? A simulation approach
}

\author{
John Robb \\ Cambridge University, United Kingdom
}

\section{A R T I C L E I N F O}

\section{Article history:}

Received 18 October 2015

Received in revised form 11 May 2016

Accepted 16 May 2016

Available online $\mathrm{xxxx}$

\section{Keywords:}

MNI

Skeletal part representation

Collective tombs

Funerary taphonomy

Simulation

Equifinality

\begin{abstract}
A B S T R A C T
Two cornerstones of conventional wisdom in interpreting commingled assemblages are (a) the MNI provides reliable information about how many individuals were deposited there, and (b) the distribution of skeletal parts provides information about ritual processes such as primary vs. secondary deposition. Both of these involve assumptions about the taphonomic processes linking the original depositions and the assemblage which archaeologists recover. Yet, it is almost impossible to investigate these processes directly in ethnoarchaeological, forensic or experimental settings, particularly observing the effects of the passage of long time spans and repeated disturbance events. This paper reports an attempt to understand these relationships and processes through simulation of a hypothetical prehistoric collective tomb. The key results are (a) there is no linear or proportionate relationship between the number of bodies originally deposited in a tomb and the MNI excavated there; indeed, in many situations, for taphonomic reasons, the MNI quickly reaches a low ceiling and levels off regardless of how many individuals were actually placed in the tomb, and (b) lack of small and fragile bones provides a very poor criterion for differentiating between burial within a tomb and secondary deposition there following primary burial elsewhere. However, skeletal part representation can prove informative about other processes such as selective curation of crania and removal of bones from tombs for funerary use elsewhere.
\end{abstract}

(c) 2016 The Author. Published by Elsevier Ltd. This is an open access article under the CC BY license (http://creativecommons.org/licenses/by/4.0/).

\section{Introduction}

When archaeologists try to interpret commingled assemblages, the two most common questions to ask are: how many people were deposited, and how they were deposited? We conventionally answer the first question by inventorying the assemblage and calculating the MNE and MNI. The underlying assumption here is that there is a proportionate or linear relationship between the MNI and the number of individuals originally deposited; even if the MNI is only a rough underestimate, a small MNI suggests a small burial population, and a large MNI suggests a large burial population. For the latter question, we typically calculate skeletal part representation. The common assumption is that proportionate representation of all parts of the skeleton suggests primary deposition, while a relative lack of small or fragile bones implies secondary deposition, perhaps following processes such as excarnation.

Conceptually, both assessing MNI and using part representation to characterize burial ritual are reconstructive processes: we are using features of the preserved bone assemblage to reconstruct the processes which created it. This is a classic Middle Range Theory problem, as

E-mail address: jer39@cam.ac.uk.
Binford (1980) originally posed the question: can we relate the static evidence we study to the dynamic processes which created it? Many other works have addressed other aspects of how bone assemblages form, including processes such as weathering, water transport, carnivore gnawing, and so on. However, almost no work has been done to systematically relate depositional processes to MNI calculations and element representation curves. Skeletal part representation is readily compiled from a well-excavated site and can potentially furnish a fundamental tool for taphonomic interpretation. This method, however, is based mostly upon its general logic and anecdotal evidence; it has rarely been directly tested. The purpose of this paper, therefore, is to critically assess the relationship between ritual processes and patterns in the resulting element representation.

\section{How human skeletal assemblages form}

In the most general sense, human skeletal assemblages form by a combination of three processes: deposition, removal and in situ destruction. The space we excavate can be conceptualized as a box which collects bones as they are deposited in it or on it, whether they are deposited inside an intact body (primary deposition), as body parts or disarticulated bones which have already been processed somewhere 
else (secondary deposition), or even by non-human forces, as when bones collect in a carnivore den or at the base of an eroding slope. Once the bones are deposited, they can have three destinies:

1. Some bones may be removed elsewhere, whether by humans recovering them for ritual, political, or other uses, or by non-human forces, such as by scavenging animals, wind, water or gravity.

2. Some bones may be destroyed in situ, removing them from the assemblage. Common forces of destruction include chemical dissolution by acidic groundwater, root damage by plants, physical breakage when bones are moved during subsequent depositions, and multi-causal processes when several of these factors interact.

3. The bones remaining form the assemblage potentially recoverable by archaeologists.

Upon excavation, this assemblage may pass through several other filters before becoming available to study:

1. Excavators may not recover all bones equally. Excavators may collect bones in a "grab sample" as they see them, with variable levels of recovery depending upon the excavator's expertise in recognizing bones, soil conditions, and excavation policy (many older excavations, for example, focused principally upon crania, mandibles and major long bones, and recovered other elements only casually). Moreover, excavators may recognize and recover small or unfamiliar bones such as wrist bones more readily in articulated burials than in jumbled masses of bone or loose in soil. Other excavations may have osteologically-trained excavators, and/or may sieve sediments systematically to recover all bones.

2. Once a collection makes it to the archaeological laboratory or museum, it still remains dynamic: as anyone who has studied an old collection will know, specimens are often removed for storage in different places, taken away for specialist study, mislabelled or lost. For instance, complete skeletons are often curated separately from mixed fragments from the same context; crania, mandibles, teeth, or complete long bones may be pulled from collections for specialist study or for display. Frequently, once collections are separated, they may never be reunited.

Both of these factors affect different skeletal elements differentially, and for analysis of part representation, collections can rarely be taken at face value; usually a careful collection history is an essential preliminary. For example, a Neolithic collection from Guernsey excavated by antiquarians in the 1840 s contained 22 mandibles but only 8 crania (Schulting et al., 2010). Does this reflect an unusual mandible-focused Neolithic rite? It is equally likely that more crania were originally present but that the Victorian excavator sent them away for craniological study elsewhere without leaving any record of them.

\section{Vital statistics of an assemblage: MNE, MNI, element representa- tion, and bone representation indices}

Methods for characterizing assemblages statistically are simple and widely used in much the same form. It seems possible that aDNA analysis may at some point render this methodology obsolete by allowing us to characterize individuals in the assemblage genetically, but for now, the basic steps include:

1. The assemblage is inventoried. Normally, a census is conducted by tabulating how many of each element is present. Larger bones are typically tabulated in terms of sub-regions whose presence and absence can be tabulated separately; for instance, a long bone may be inventoried as five regions (proximal epiphysis, proximal third of shaft, middle third of shaft, distal third of shaft, and distal epiphysis). This prevents fragments of different regions from being counted as representing different specimens when they could, in fact, originate in the same specimen, now broken. Small bones may be tabulated as a single unit; the cranium and pelvis may be tabulated in many regions. The two most common systems for dividing the skeletons into census regions are that of Buikstra and Ubelaker (1994), and that of Knüsel and Outram (2004). The former recommends that each region is graded in terms of how much is preserved (whole, more than half, less than half, small fragment). The latter, which uses regions drawn from animal anatomy to allow comparison between human and faunal assemblages, simply counts the presence or absence of a region.

2. To calculate the Minimum Number of Elements (MNE), one simply uses the largest number of a specific region from a particular bone. For example, if there are five distal epiphyses from left humeri present and there are only two or three of each of the other regions, there must have originally been at least five left humeri present.

3. To calculate the Minimum Number of Individuals (MNI), one simply determines the largest value of the MNE for the various bones in the skeleton. For instance, if there are five left humeri, seven right humeri, eight right femora, and ten left temporal bones, the bones must originally have come from at least ten bodies. (Obviously, calculations have to take into account bones of which the body contains multiple specimens must be adjusted; ten thoracic vertebrae may represent a single individual, while ten left temporal bones must represent ten individuals).

4. Finally, the MNE for different bones can be used to assess how different bones are represented proportionally. For present purposes, the Bone Representation Index (which counts elements known to be present) is more relevant than measures such as the Anatomical Preservation Index and the Qualitative Bone Index, which measure how much bone is remaining within each region to be observed (Bello et al., 2006). The Bone Representation Index (BRI), which was first defined formally by Dodson and Wexlar (1979) but seems to have been arrived at independently by human osteologists as well, measures how many of an element are present in comparison with how many would be present if each of the MNI were represented by a complete body. The general formula is:

$B R I=\frac{(\mathrm{MNE}) \times 100}{(\text { number of element in complete skeleton }) \times \mathrm{MNI}}$

For example, if there are 16 carpal bones in a complete body and the MNI is 10 , a complete assemblage would contain 160 carpal bones $(B R I=100 \%)$. If only 40 carpals were found, the BRI would be (40/ $160) \times 100$, or $25 \%$. (Note that we might wish to calculate the BRI for carpals as a group, as a general measure of how well-preserved small bones are, even when we would identify and tabulate each kind of carpal bone individually in a detailed skeletal inventory). In the same assemblage, we would expect to find 20 tibiae; if we found 7 left tibiae and 6 right tibiae, the BRI for all tibiae $=(13 / 20) \times 100=65$.

In practice, MNE and MNI calculations for a site can be done in several ways which will yield different results. One practical issue is whether one tabulates the MNE mechanically, as described above, or instead lays out all specimens and counts them by eye, including information on bone size, colour, texture, etc. Another practical issue is whether one includes all tabulated fragments, or only those which represent half or more of a region through some formal measure of preservation such as the Anatomical Preservation Index, so that they must represent a unique specimen distinct from all the other fragments present. One can create separate MNEs and MNIs for adults and juveniles, even for males and females, and then add them to get a total. Finally, one can tabulate a site assemblage as a whole, or tabulate different contexts separately on the assumption that no bone movement between them has occurred. As this suggests, the MNE and MNI for an assemblage are not absolute estimates but a range, contingent upon various analytical decisions. 


\section{Testing how bone assemblages form: why simulate?}

Once MNI and element representation curves are calculated, we have to interpret them. This is the central question of this paper: how do MNI and element representation curves relate to the processes which form assemblages? Does MNI have a consistent relationship to the number of bodies deposited in a site? Does element representation really reflect funerary rituals?

Given the centrality of these questions, there are surprisingly few means to actually test these questions empirically. Forensic studies can inform us about site formation processes in the short term - how an exposed body is scavenged by carnivores, for example - but they rarely have time depth to reveal gradual processes over longer spans or sufficient assemblage size to reveal statistical patterns. We rarely have the chance to study modern sites ethnoarchaeologically in situations where we both know the funerary processes involved and have access to the resulting assemblage. We can occasionally study assemblages from sites where the funerary processes are well-understood from other archaeological or historical information, but there are few assemblages whose ritual parameters are definitely established.

Simulation provides an alternative approach. Simulations allow us to vary parameters in known ways and observe the effects upon outputs such as MNI and element representation. They are especially useful for testing the effects of periodic or rare events, and for seeing how small, gradual effects may accumulate. Simulations are not without limitations. They follow the universal computing rule of "garbage in, garbage out": results are only as plausible and interesting as the programming and inputs used to generate them. Moreover, simulations are unforgivingly concrete. The computer cannot process vague indications such as "poor bone preservation": it demands specific parameters such as " $5 \%$ bone destruction per century." Clearly, we never actually know most of these parameters, although we can try to estimate them as realistically as possible.

Given these limitations, it is essential to use simulations strategically. It is rarely useful to try to create a single simulation which reproduces reality in all its complexity; this will inevitably be wrong in some way, and its very complexity is likely to render any results indeterminate or arguable. Instead, it is more useful to abstract the basic relationships we want to explore and to run the simulation many times varying basic parameters widely, to explore the nature of these relationships. This paper, therefore, explicitly does not try to reproduce the processes forming commingled skeletal assemblages in all their detail and complexity; it simply aims at testing some general principles of interpretation, especially those which intuitively underlie common bioarchaeological interpretations.

\subsection{Designing a simulation: tomb maker}

The basic relationships modelled here are simple. A tomb (or any other burial space) is built. As time passes during its use-life, bodies are deposited in it at a given rate. Once deposited, all the bones in the tomb lose a given amount of bone periodically from in situ decomposition. Moreover, since each new burial disturbs and re-arranges previous burials, each new burial potentially degrades earlier burials by a given amount, potentially destroying some of their bones. Both in situ destruction and disturbance affect fragile and robust bones at different rates. After the tomb ceases to be used, the bones continue to decompose in situ until the tomb is excavated. It is easy to enumerate the factors this model leaves out, and one could easily add additional layers of complexity, but even this simple model reveals some relatively robust results about how bone assemblages are formed.

The simulation was constructed in a simple, user-friendly modelling package, Stella 7.0 by HPS Software. Time parameters include how long the tomb was actively used, how long its post-use history is, and the rate of burials per century. How much each burial degrades preceding burials is expressed as a rate (e.g. with each new deposition the existing assemblages is reduced by $\mathrm{x} \%$ ). How much bone is lost each century to in situ destruction is similarly expressed as a rate of loss. Both of these can be set to affect different categories of bones differently; this feature can be used to model differential curation or destruction of different categories of bone.

Once the simulation begins, in each "year" it first generates burials. When a burial is added to the tomb, it contributes 2 bones (cranium and mandible) to the "skulls" category of the assemblage, 24 bones to the "vertebrae", 14 bones (clavicles, humeri, radii, ulnae, femora, tibiae, fibulae) to "long bones", 6 bones (sternum, scapulae, ossa coxae and sacrum) to "flat/ irregular bones" and 106 bones to "hands and feet". It also destroys a set proportion of each category of bones in the existing assemblage, as these bones are disturbed and degraded by the new deposition. In addition, in each year, a set proportion of each category of bones in the existing assemblage is destroyed due to normal in situ decomposition. When a bone is "destroyed," it is simply subtracted from the identified assemblage and added to the category "unidentifiable or destroyed." After the years representing the use-life of the tomb are run, no more burials are added, and the assemblage remains stable until it ends at "excavation", except for the bones subtracted annually due to in situ decomposition.

The rest of the model simply tracks and reports the results, tabulating the total number of individuals put into the tomb, the percentage of the overall assemblage which has been destroyed or rendered unidentifiable, the minimum number of individuals (MNI) represented by each category of bones in the resulting assemblage, and the maximum MNI from all categories of bones. MNI here is calculated in a slightly simplified way, based upon the total number of bones in a category such as "long bones" rather than numbers of individual elements such as humeri, radii, ulnae, etc. This slightly underestimates the MNI, but estimating MNI separately for each bone would require additional assumptions of bone destruction rates for humeri differently from that for radii, ulnae, and so on.

As a baseline model of how assemblages form, this provides a straightforward and simple way to explore a process the basic parameters of which can only be estimated in any case. The key parameter to be estimated is the pace of bone destruction. Estimating in situ bone loss as an annual rate of destruction is problematic, we do not know if bone loss proceeds linearly, accelerates or decelerates over time, and rates will vary immensely between sites depending upon local ground conditions. Estimating how much new burials degrade preceding ones is very difficult, though re-handling dry bones can cause considerable damage, particularly to spongy bones and to epiphyseal ends of bones (Caffell et al., 2001). Moreover, there may be a feedback relationship between mechanical breakage and chemical dissolution, as well as differential decomposition for the bones of adults and children. In the simulation runs, below, except where noted otherwise, destruction rates for "flat" bones are set at twice those for "long" bones and "skull" bones, and "vertebrae" and "hand and foot" bones are set to five times this. Element representation commonly found in moderately preserved single primary inhumations suggests that these are potentially plausible ratios (Cox and Bell, 1999, Mays, 1992, Ubelaker, 2002). While these factors deserve further exploration, this simple model still provides some relatively useful insights.

This model is a simplified representation, a general baseline for the great variety of ancient ways of depositing bodies. Once a baseline is modelled, the effect of many variations is relatively predictable; others could potentially be explored through further modelling of specific scenarios. For example, it models a single burial space, while many prehistoric tombs contained multiple burial spaces, among which bones were regularly moved. A multi-chambered tomb, however, is conceptually an aggregate of single spaces, and bone movement between spaces presumably would accelerate processes of selection and destruction. Again, ancient people may have sometimes wrapped bodies in shrouds; this could readily be modelled as increasing the retention of small bones during disturbance, and perhaps enhancing general preservation to 
some degree. Similarly, a key variable is clearly the care with which ancient people may have handled and transported bones. Handling old bones, even in archaeological and anatomical collections, almost always entails some risk of loss and damage, and the disorder evident within most prehistoric tombs suggests that ancient people generally were not overly concerned with preventing loss and destruction of most bones. This is therefore the assumption modelled here. However, where prompted by archaeological evidence, one could easily model more detailed scenarios in which care was taken to retain small bones or to keep bones intact. But exploration with modelling a fairly extensive range of scenarios (see below) suggests that, as long as one accepts the basic model architecture, adapting it to such specific scenarios may help us understand a particular archaeological context better, but the overall direction of the findings will remain much the same.

\section{How does MNI relate to the number of bodies deposited?}

One of the first questions an osteologist is asked about a collective deposition is how many people it contains, and this question often forms an important starting point for social interpretations. For example, Neolithic tombs in Britain usually contain less than 50 skeletons, and very rarely contain more than 100 . In Britain and Ireland, for example (see reviews in Beckett and Robb, 2006, Smith and Brickley, 2009), a MNI of 35-42 was found in Hazleton North, 14 at Wayland's Smithy, 46 at West Kennet, less than 10 at Haddenham, and around 40 at Parc Le Breos. In Ireland, most court-tombs, wedge tombs and passage graves have relatively few (4-5 at Newgrange, and 24 at Fourknocks; the $30+$ at Audleystown is regarded as a large assemblage. Only at Tara (over 100) and Quanterness (157) were substantially larger groups found. This pattern is common elsewhere; for instance, third-millennium (Copper Age) collective tombs in the Central Mediterranean almost always yield MNIs of one to two dozen people at most, and the same is true for Bronze Age tombs in the Eastern Mediterranean. Collective burial assemblages only rarely rise above about 100 individuals. Exceptions tend to be either complex tombs with multiple chambers or burial foci (e.g. the Brochtorff Circle at Xaghra, Gozo, with some $400+$ bodies (Malone et al., 2009)), tombs with multiple levels of burials intentionally sealed between episodes of deposition (as in some TRB (Funnel Beaker) tombs), or depositions left undisturbed after a single mass burial episode (as in epidemics, warfare, or "Feast of the Dead" style rites, as in the ossuaries of Nanjemoy Creek I and II (Ubelaker, 1974)). This small number of burials has often been taken to imply that only selected people were buried in megalithic tombs. Prehistoric populations must have included many more people - indeed, the groups building tombs must have been more numerous than the people found buried within them. Does this mean that only special people were buried in collective tombs?

Here, simulation is used to explore the relationship between the number of people originally buried in a tomb and the number excavated by archaeologists thousands of years later. The "Tomb Maker" simulation model described above was run multiple times with varying sets of parameters. In this set of illustrations, the simulated tomb is used from $3000 \mathrm{BCE}$ to $2000 \mathrm{BCE}$, followed by 4000 years of post-use life before it is "excavated". About 50 burials per century are deposited, so the total number of burials deposited in the tomb is about 500.The range of results can be summarized briefly here.

- If bones are not destroyed in any way, whether by in situ destruction or by subsequent depositions, the relationship is simple: 1000 bodies in equals 1000 bodies out, and the MNI provides a reliable guide to original burial numbers. (This is the case, for instance, with well-preserved single burials, where the MNI of 1 for each grave equals the number of skeletons actually deposited. It is also the case with very well-preserved materials, as in forensic examinations).

- If bones are only destroyed through in situ decomposition due to factors such as chemical dissolution, root action, and mechanical compression from soil pressure, the assemblage will gradually stabilize at a fraction of its original size. In Fig. 1, for example, destruction from subsequent inhumations is set to zero, while in situ decomposition is varied from 0 (top line) to $10 \%$ (bottom line). Over the 5000 year span, in situ decomposition has a substantial cumulative effect. A loss rate of $1 \%$ per century reduces the MNI by about $30 \%$; a $2 \%$ loss rate reduces the MNI by about $60 \%$, and so on. With $10 \%$ destruction per century, the MNI comes to around $1 \%$ of the number of original burials. Thus, gradual rates of in situ decomposition can reduce the final MNI substantially.

- If each deposition degrades previous depositions, even if only slightly, the effect is dramatic and counter-intuitive. In the simulations reported in Fig. 2, only mechanical destruction during subsequent inhumations occurs; in situ decomposition is set to zero. In the first run, our hypothetical people depositing new bodies were meticulously careful not to damage or destroy any pre-existing bones; in the next run, each new burial destroyed $1 \%$ of previously deposited bones, then $2 \%$ and so on up to $10 \%$. The results are striking. When each new burial does not damage earlier bones in any way (the top line), the MNI rises steadily through the use-life of the tomb, and then remains level at 500 burials until the present. But if each deposition destroys even $1 \%$ of earlier bones (the second line from top), the MNI never exceeds 100 ; in other words, the cumulative effect is to destroy over $80 \%$ of the assemblage. With $2 \%$ destruction, over $90 \%$ of the assemblage is

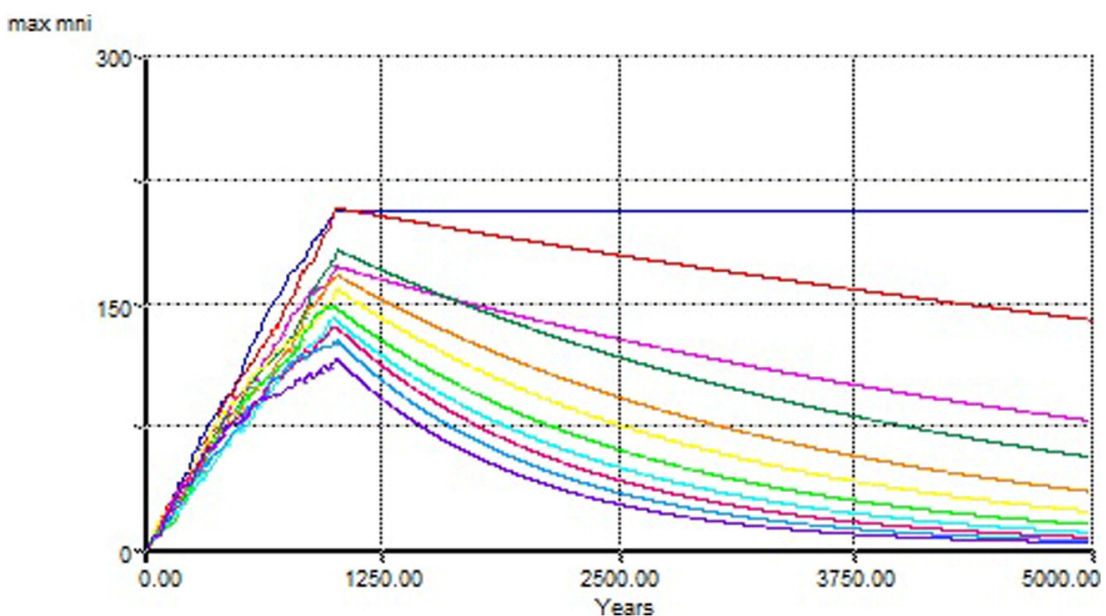

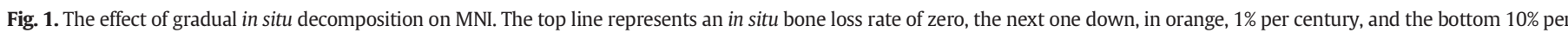
century. 
max mni

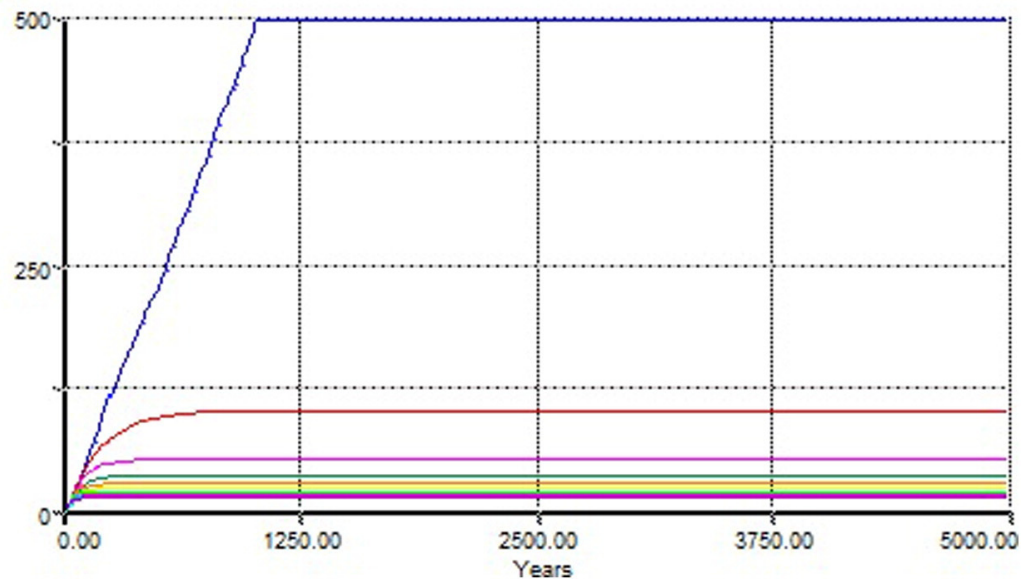

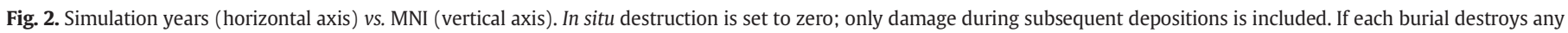
percentage at all of earlier bones, the MNI quickly reaches a ceiling which represents only a fraction of the real number of burials deposited.

destroyed and the MNI hits a ceiling of about 50 , and so on. To make the same point in another way, here (Fig. 3) we fix the rate at which each burial degrades previous ones to $1 \%$ and vary the number of burials put into the tomb instead (in situ destruction remains set to zero). The lowest line represents 10 burials per century, or 100 total bodies placed into the tomb. The next line up represents 20 burials per century or 200 total, and so on until the top line, which represents 100 burials per century, or 1000 total. As this shows, with 100 bodies entering the tomb, the MNI reaches about 60; with 200 entering the tomb, the MNI reaches about 87; with any level of burial above this, it reaches between 90 and 100. Running the simulation with different values for other parameters reproduces the same pattern of equifinality. Cumulative destruction creates a ceiling for the MNI. Thus, if we excavate a MNI of 95 people in this tomb, they could represent 300 people originally interred there, or they equally well could represent 1000.

- Finally, let us consider the effects of both kinds of bone destruction together (Fig. 4). For the 1000 years of the use-life of the tomb, the bones are subjected to $1 \%$ destruction from each subsequent burial plus $1 \%$ bone loss per century from in situ decomposition; these are at the conservative end of the rates modelled above. After the uselife of the tomb the remains are subjected to only in situ decomposition. The lowest line represents 10 burials per century or 100 total burials in the tomb. The next line represents 20 burials per century or 200 total burials, and so on up to 100 burials per century and 1000 burials in all. During the use-life of the tomb the MNI curves upwards as new burials are added, but levels off due to burial-related breakage; after use of the tomb the MNI gradually declines as environmental factors take their toll. With 100 bodies in all, we finish with an MNI just below 50. For all the other runs, regardless of whether there are 200 or 1000 people actually deposited in the tomb, the final MNI is between 60 and 70 .

This simulation was run many times with different configurations of variables. In virtually all cases, a similar result was obtained; the MNI only reached an appreciable fraction of the actual number of burials when both kinds of destruction were implausibly low (0.001: one bone in a thousand destroyed by each subsequent inhumation or lost to in situ decomposition in each century)(Fig. 5).

These results provide a clear cautionary tale. Any model is a simplification; here, the rates of bone destruction are gross estimates, we rarely know the real duration of tomb use, and the model assumes constant rates of destruction. But these simplifications should not affect the overall relationships revealed. As long as each burial destroys previous bones to some degree, or as long as there is an appreciable rate of in situ decomposition, the excavated MNI will be only a fraction of the original population buried in a tomb. This is presumably so regardless of the

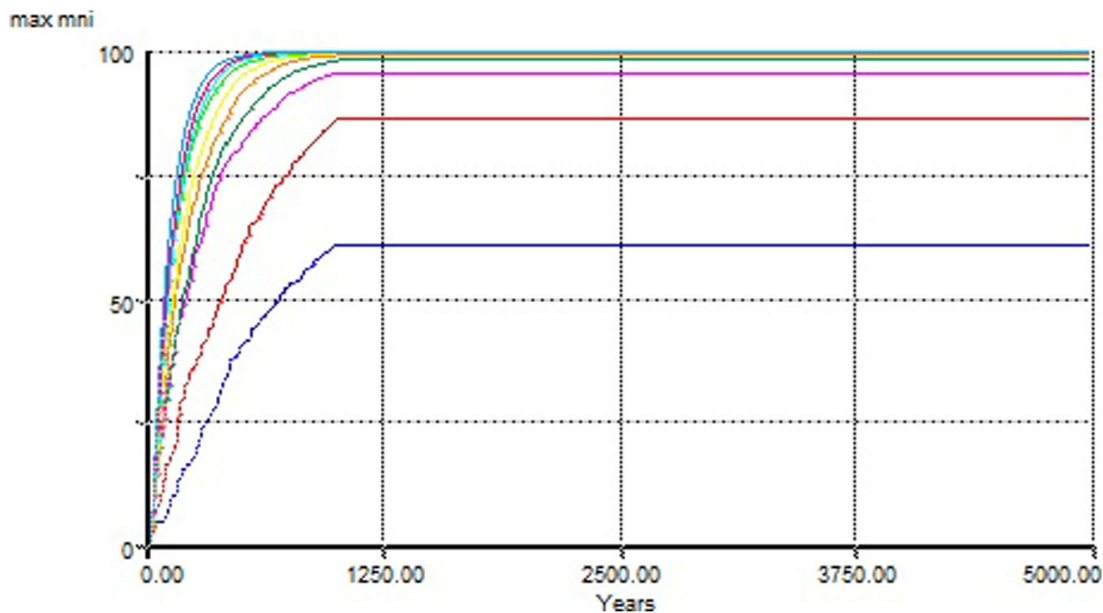

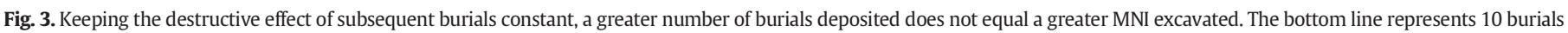
per century of use-life or 100 burials total; the top line 100 burials per century or 1000 burials total. In no case does the final MNI exceed 100 . 


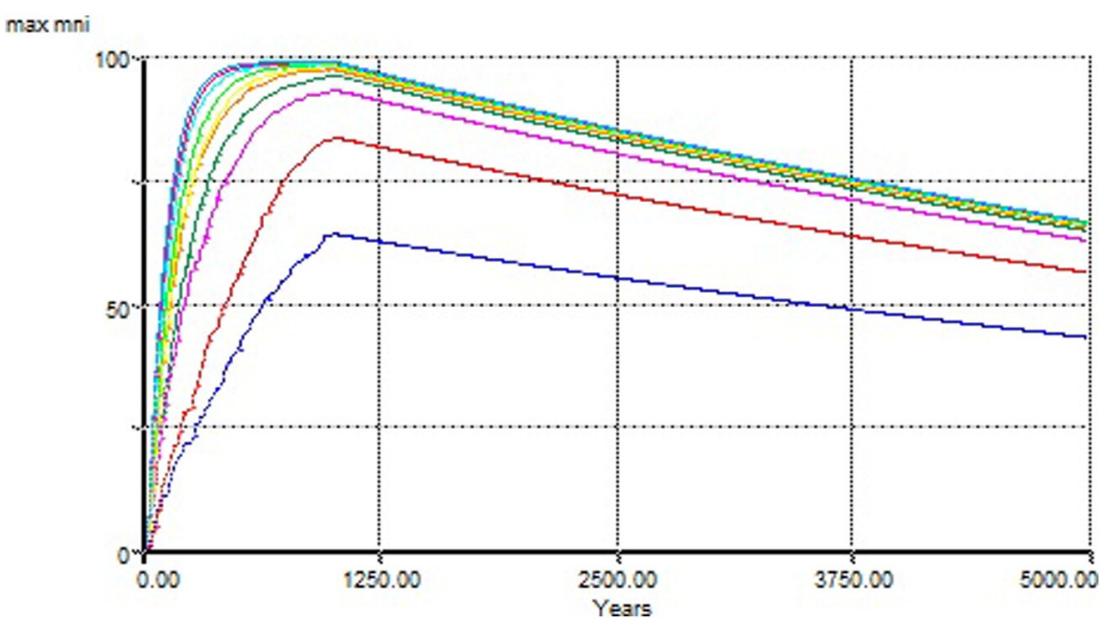

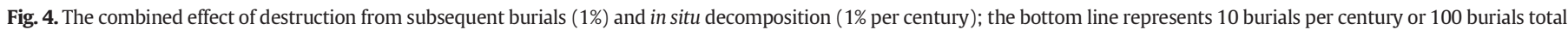
the top line 100 burials per century or 1000 burials total. Regardless of whether 100 or 1000 people are buried in the tomb, the MNI never exceeds 70 .

actual use-life of the tomb; 100 subsequent burials will presumably damage earlier burials to an equal extent whether they take place over 50 years or 500 years (an important consideration given the recent discovery that many Neolithic tombs may have had quite short use-lives (Bayliss and Whittle, 2007)). More importantly, MNI will not represent a regular or constant proportion of the original tomb population. Instead, collective tomb assemblages reach a ceiling they are unlikely to go above, regardless of how many people were originally buried in them. Thus, except in occasional cases of large sites with multiple burial spaces or episodic mass interments, MNI in collective depositions probably has far less to do with the actual number of people buried in a tomb than with the taphonomic conditions of bone destruction. For all we can tell, where collective tombs were used, every member of Neolithic society may well have been deposited in them. This also implies that Neolithic "tombs" have little to do with our modern concept of tombs as permanent repositories for the intact dead. Their function was not to preserve the bodies of the dead indefinitely; if anything, they probably served as technologies for very slowly destroying them.

\section{Part representation and funerary practices}

The second common use of assemblage data is to reconstruct funerary rites, primarily through part representation. A complete skeleton includes a cranium, mandible, 24 vertebrae, 24 ribs, 14 long bones, 6 flat or irregular bones (sternum, scapulae, sacrum, ossa coxae), and 108 small bones (hands, feet and patellae). Some of these degrade more

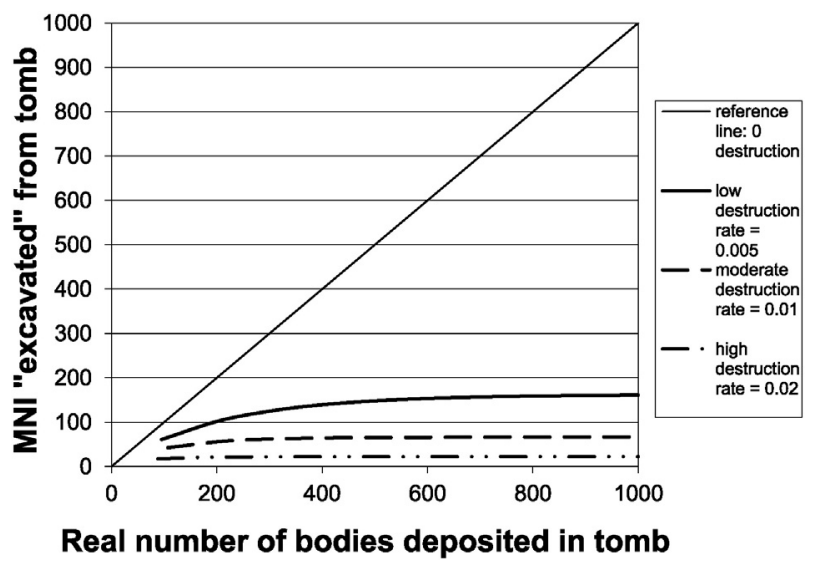

Fig. 5. Summary graph comparing people buried in tomb (horizontal axis) with MNI excavated (vertical axis) for runs with different levels of bone destruction. readily than others, but an undisturbed primary inhumation should have all areas of the body represented to some degree. When a primary deposition is disturbed, fragile bones may be disproportionately destroyed, and small bones may be lost more readily than large ones. The situation may, in fact, be far more varied. When a deposition is disturbed, whether or not it is moved in space, people may treat different bones differentially for cultural reasons. It is not uncommon for people in the past to protect or retain crania or major long bones preferentially, to disregard bones they think are less important, or to remove particular bones from the deposition for use elsewhere. It will be obvious that these form a continuum, rather than distinct categories with highly distinct signatures (for instance, a concern with heads may range from collecting crania alone to simply a tendency to put them to one side rather than treading on them while clearing a space inside a cluttered tomb).

How can we recognize these taphonomically? We usually can recognize undisturbed primary depositions readily and unproblematically from skeletal articulation. Beyond this, it is common in taphonomic interpretations to treat loss of fragile and small bones as a diagnostic criterion for secondary burial. But do these different processes really leave distinct and recognizable signatures of element representation?

To test this, a scenario of the Tomb Maker simulation was created to represent a collective tomb built at $3000 \mathrm{BCE}$, used for 500 years, and then left undisturbed except by in situ decomposition for another 4500 years. About 50 individuals are deposited there each century, giving a total of about 250 individuals deposited. This simulation was then run repeatedly with varying parameters (Tables 2, 3; various other scenarios and control runs were also run but are not reported here). The Bone Representation Index was then calculated using the methods outlined above. For simplicity, results are grouped into broad taphonomic categories of bones which share important taphonomic features in a broad sense (Table 2). (See Table 1.)

\subsection{Negative results: does element representation really distinguish sequential primary deposition from secondary deposition?}

Fig. 6 shows the element representation curves which result from simulating different funerary practices. The most important finding here is that the lack of fragile and small bones does not provide a reliable means of distinguishing between sequential primary inhumation and secondary burial. Archaeologists often assume that a mass of disarticulated bones which has almost no vertebrae, hand and foot bones in it must have been redeposited from somewhere else, perhaps following a process such as excarnation. But in fact, this may not be the case: both secondary depositions and assemblages which form simply 
Table 1

General categories of funerary treatment and their potential element representation signatures.

\begin{tabular}{|c|c|c|}
\hline Practice & Examples & $\begin{array}{l}\text { Expected part } \\
\text { representation }\end{array}$ \\
\hline $\begin{array}{l}\text { Undisturbed primary } \\
\text { deposition }\end{array}$ & $\begin{array}{l}\text { Single graves; mass } \\
\text { burials in a single event }\end{array}$ & $\begin{array}{l}\text { All elements present, } \\
\text { varying according to level } \\
\text { of in situ bone destruction }\end{array}$ \\
\hline $\begin{array}{l}\text { Sequential deposition } \\
\text { (e.g. accumulation over } \\
\text { time of single } \\
\text { depositions in the same } \\
\text { space, with each new } \\
\text { deposition disturbing } \\
\text { previous ones) }\end{array}$ & $\begin{array}{l}\text { Many European } \\
\text { prehistoric collective } \\
\text { tombs }^{1}\end{array}$ & $\begin{array}{l}\text { In addition to in situ bone } \\
\text { destruction, } \\
\text { under-representation of } \\
\text { smaller and fragile bones } \\
\text { which are more readily } \\
\text { destroyed or lost upon } \\
\text { disturbance from later } \\
\text { depositions }\end{array}$ \\
\hline $\begin{array}{l}\text { Secondary deposition (e.g. } \\
\text { re-deposition of an } \\
\text { assemblage which has } \\
\text { already been given } \\
\text { some previous } \\
\text { treatment such as } \\
\text { primary burial or } \\
\text { excarnation elsewhere) }\end{array}$ & $\begin{array}{l}\text { Re-deposition in } \\
\text { ossuaries (e.g. "Feast of } \\
\text { the Dead" style rites) }\end{array}$ & $\begin{array}{l}\text { In addition to in situ bone } \\
\text { destruction, } \\
\text { under-representation of } \\
\text { smaller and more fragile } \\
\text { bones which are more } \\
\text { readily destroyed or lost } \\
\text { during transfer from the } \\
\text { place of primary } \\
\text { deposition }\end{array}$ \\
\hline $\begin{array}{l}\text { Cultural selection of } \\
\text { bones (e.g. sequential } \\
\text { primary deposition or } \\
\text { secondary deposition, } \\
\text { but specific elements } \\
\text { are intentionally } \\
\text { collected, retained, or } \\
\text { protected from } \\
\text { destruction - most } \\
\text { often the cranium) }\end{array}$ & $\begin{array}{l}\text { Cranial curation: } \\
\text { collections of trophy or } \\
\text { ancestral crania (and } \\
\text { museum craniological } \\
\text { collections!). } \\
\text { Archaeologically: Kunji } \\
\text { Cave (Emberling et al., } \\
\text { 2002) }\end{array}$ & $\begin{array}{l}\text { Like secondary } \\
\text { deposition, but with } \\
\text { over-representation of } \\
\text { the element of interest }\end{array}$ \\
\hline $\begin{array}{l}\text { Residual bone } \\
\text { assemblages (e.g. } \\
\text { remaining bones left in } \\
\text { situ following removal } \\
\text { of elements by } \\
\text { disturbance, for } \\
\text { secondary deposition or } \\
\text { other uses) }\end{array}$ & $\begin{array}{l}\text { A broad category } \\
\text { comprising scattered } \\
\text { remains from disturbed } \\
\text { primary or other burials } \\
\text { ("scattered bone"), } \\
\text { left-overs following } \\
\text { cultural selection (e.g. } \\
\text { Poulnabrone Neolithic } \\
\text { tomb (Beckett, 2011), } \\
\text { and disposal of unwanted } \\
\text { elements (such as } \\
\text { medical waste) }\end{array}$ & $\begin{array}{l}\text { Highly variable, but } \\
\text { generally highly variable } \\
\text { inconsistent } \\
\text { representation across } \\
\text { zones of the skeleton; } \\
\text { often over-representation } \\
\text { of small, peripheral, easily } \\
\text { transported, or culturally } \\
\text { unimportant elements, } \\
\text { creating converse pattern } \\
\text { to secondary deposition } \\
\text { and cultural selection }\end{array}$ \\
\hline
\end{tabular}

1 This is the scenario simulated in the discussion of MNI above.

by adding bodies to a confined space are likely to have very low representation of fragile and small bones. For a given level of preservation, secondary burials have relatively fewer of these bones, but the distinction is not large and element representations from both are quite similar. The reason is clear: as long as these bones are more likely than long bones or crania to be destroyed from in situ causes or from disturbance when a burial space is re-opened and re-used, time and tomb re-use lead to low representation which mimics the pattern expected from secondary deposition. Thus, we encounter a situation of equifinality: depending upon preservational conditions, primary burials with in situ bone loss, disturbed primary inhumations, secondary depositions, and secondary depositions of already disarticulated material may all display similar patterns of element representation.

\subsection{Positive results: residual bone, selection of elements and other departures from the preservational baseline}

More encouragingly, while less representation of small and fragile bones forms a common baseline which does not distinguish differing funerary treatments, departures from this baseline often stand out quite clearly. The pattern of "residual deposition" in which major long bones and crania are removed and the rest of the skeleton is deposited, provides a good example. If we excavate a collective tomb in which representation of hand and foot bones is on the same level of magnitude as
Table 2

Settings for simulation parameters

\begin{tabular}{|c|c|}
\hline $\begin{array}{l}\text { Categories of } \\
\text { bones }^{\text {a }}\end{array}$ & $\begin{array}{l}\text { "cranial": cranium and mandible. "vertebrae": vertebrae. "long } \\
\text { bones": clavicle, humerus, radius, ulna, femur, tibia, fibula. } \\
\text { "flat/irregular bones": scapula, sternum, ossa coxae, sacrum. } \\
\text { "hands and feet": carpals, tarsals, metapodials, phalanges, and } \\
\text { patellae. }\end{array}$ \\
\hline $\begin{array}{l}\text { Level of } \\
\text { preservation }\end{array}$ & $\begin{array}{l}\text { for "excellent", both in situ destruction and destruction due to } \\
\text { each subsequent burial were set to } 0.0005 \% \text {; for "very good", } \\
\text { both were set to } 0.01 \text {; for "good", to } 0.015 \text {; for "moderate", to } \\
0.02 \text {; and for "poor", to } 0.025 \text {. }\end{array}$ \\
\hline $\begin{array}{l}\text { Differential } \\
\text { destruction }\end{array}$ & $\begin{array}{l}\text { As above, it was assumed that vertebrae, flat bones, and hands } \\
\text { and feet were more susceptible to destruction as crania and } \\
\text { long bones. }\end{array}$ \\
\hline Secondary burial & $\begin{array}{l}\text { In the "secondary burial" scenarios, for each "burial", all cranial } \\
\text { and long bones are deposited, but only half the number of } \\
\text { vertebrae, flat bones and hand and foot bones are. }\end{array}$ \\
\hline Residual burial & $\begin{array}{l}\text { In the "residual burial" scenarios, for each "burial", all } \\
\text { vertebrae, flat bones and hand and foot bones are deposited, } \\
\text { but only half the number of cranial and long bones. }\end{array}$ \\
\hline Cranial curation & $\begin{array}{l}\text { In the "cranial curation" scenarios, the destruction of cranial } \\
\text { bones when new depositions are made within the tomb is set } \\
\text { to half what it would otherwise be; other parameters are } \\
\text { unchanged. }\end{array}$ \\
\hline
\end{tabular}

${ }^{a}$ Vertebrae and hand/foot bones were modelled as five times more susceptible to destruction and loss as crania and long bones; flat bones were modelled as twice as susceptible to destruction and loss as cranial and long bones, reflecting the robust nature of portions of the scapula and pelvis. A separate set of simulations which assumed that destruction and loss affect all bones equally was carried out but is not reported upon here.

b Ribs were not included because it is difficult to assess realistically the actual number present in most commingled and fragmented assemblage, even when counting their more distinctive zones.

that of major bones (such as at the Irish Neolithic tomb of Poulnabrone, where the MNI was provided from hand bones (Beckett, 2011, Beckett, 2005)), we may have strong grounds for thinking that the assemblage is partly residual and reflects the removal of crania or long bones for another use elsewhere.

The other treatment which may be discernible is curation of specific bones. Archaeologists sometimes recover contextual evidence of particular attention to specific bones. For example, in collective burials of the Iranian Bronze Age, disarticulated crania were sometimes placed in protected areas, set upright on their base, or decorated with beads (Emberling et al., 2002). More casually, even while moving the remains of previous depositions, people may simply place some bones more carefully than others or try not to damage them. Does such behavior affect element representation? Fig. 7 shows the effect of cranial curation upon element representation curves. Crania and long bones have a comparable level of resistance to destruction (see for example data in Waldron (1987)); while crania are generally more fragile than long bone shafts, they are uniquely-shaped bones and can often be identified from small fragments when long bones may be reduced to unidentifiable shaft fragments. Thus, as a general rule of thumb, in most assemblages, representation of crania and major long bones such as femora and tibiae is approximately equal. When crania are preferentially curated, they are over-represented. This in turn affects the analyses. Since cranial bones provide the MNI to which the bone representation index is keyed, this depresses the BRI of all other elements.

\section{Discussion: equifinality and informative signals}

An oft-quoted axiom of simulation modelling states: "all models are wrong; but some are useful". Simulations are not intended to replicate the world in all its complexity; they are intended to explore important relationships heuristically. The simulation here does not try to consider all the variables which affect bone assemblage formation. Instead, it explores a few key relationships which underlie some common interpretations of bone assemblages.

This article explores two common tropes in interpreting commingled assemblages. The first concerns how to understand the 
Table 3

Results of simulation runs exploring funerary treatment and element representation.

\begin{tabular}{|c|c|c|c|c|c|c|c|c|c|c|}
\hline \multirow[b]{2}{*}{ Run } & \multirow[b]{2}{*}{ Funerary treatment } & \multirow[b]{2}{*}{$\begin{array}{l}\text { General } \\
\text { preservation }\end{array}$} & \multirow[b]{2}{*}{$\begin{array}{l}\text { Special treatment of } \\
\text { crania }\end{array}$} & \multirow[b]{2}{*}{$\begin{array}{l}\text { Total } \\
\text { burials }\end{array}$} & \multicolumn{5}{|c|}{ Bone Representation Index (\%) } & \multirow[b]{2}{*}{$\begin{array}{l}\text { Hand/foot } \\
\text { bones }\end{array}$} \\
\hline & & & & & MNI & $\begin{array}{l}\text { Cranial } \\
\text { bones }\end{array}$ & Vertebrae & $\begin{array}{l}\text { Long } \\
\text { bones }\end{array}$ & $\begin{array}{l}\text { Flat/irregular } \\
\text { bones }\end{array}$ & \\
\hline 1 & $\begin{array}{l}\text { Sequential primary } \\
\text { deposition }\end{array}$ & Excellent & No & 249 & 113 & 100 & 11 & 100 & 38 & 11 \\
\hline 2 & $\begin{array}{l}\text { Sequential primary } \\
\text { deposition }\end{array}$ & Very good & No & 259 & 58 & 100 & 4 & 100 & 22 & 4 \\
\hline 3 & $\begin{array}{l}\text { Sequential primary } \\
\text { deposition }\end{array}$ & Good & No & 251 & 33 & 100 & 1 & 100 & 15 & 1 \\
\hline 4 & $\begin{array}{l}\text { Sequential primary } \\
\text { deposition }\end{array}$ & Moderate & No & 241 & 20 & 100 & 1 & 100 & 10 & 1 \\
\hline 5 & $\begin{array}{l}\text { Sequential primary } \\
\text { deposition }\end{array}$ & Poor & No & 259 & 13 & 100 & 0 & 100 & 7 & 0 \\
\hline 6 & Secondary deposition & Excellent & No & 246 & 112 & 100 & 6 & 100 & 26 & 6 \\
\hline 7 & Secondary deposition & Very Good & No & 236 & 57 & 100 & 2 & 100 & 17 & 2 \\
\hline 8 & Secondary deposition & Good & No & 239 & 32 & 100 & 1 & 100 & 13 & 1 \\
\hline 9 & Secondary deposition & Moderate & No & 240 & 20 & 100 & 0 & 100 & 10 & 0 \\
\hline 10 & Secondary deposition & Poor & No & 247 & 13 & 100 & 0 & 100 & 8 & 0 \\
\hline 11 & Residual & Excellent & No & 248 & 58 & 98 & 22 & 98 & 100 & 22 \\
\hline 12 & Residual & Very good & No & 237 & 28 & 100 & 7 & 100 & 69 & 7 \\
\hline 13 & Residual & Good & No & 254 & 16 & 100 & 3 & 100 & 52 & 3 \\
\hline 14 & Residual & Moderate & No & 236 & 10 & 100 & 1 & 100 & 41 & 1 \\
\hline 15 & Residual & Poor & No & 257 & 6 & 100 & 0 & 100 & 33 & 0 \\
\hline 16 & $\begin{array}{l}\text { Sequential primary } \\
\text { deposition }\end{array}$ & Excellent & Yes & 274 & 157 & 100 & 8 & 75 & 38 & 8 \\
\hline 17 & $\begin{array}{l}\text { Sequential primary } \\
\text { deposition }\end{array}$ & Very good & Yes & 256 & 90 & 100 & 2 & 64 & 22 & 2 \\
\hline 18 & $\begin{array}{l}\text { Sequential primary } \\
\text { deposition }\end{array}$ & Good & Yes & 240 & 55 & 100 & 1 & 59 & 15 & 1 \\
\hline 19 & $\begin{array}{l}\text { Sequential primary } \\
\text { deposition }\end{array}$ & Moderate & Yes & 264 & 37 & 100 & 0 & 54 & 11 & 0 \\
\hline 20 & $\begin{array}{l}\text { Sequential primary } \\
\text { deposition }\end{array}$ & Poor & Yes & 254 & 24 & 100 & 0 & 53 & 9 & 0 \\
\hline 21 & Secondary deposition & Excellent & Yes & 269 & 155 & 100 & 4 & 76 & 19 & 4 \\
\hline 22 & Secondary deposition & Very good & Yes & 256 & 90 & 100 & 1 & 64 & 11 & 1 \\
\hline 23 & Secondary deposition & Good & Yes & 262 & 57 & 100 & 0 & 57 & 7 & 0 \\
\hline 24 & Secondary deposition & Moderate & Yes & 256 & 36 & 100 & 0 & 54 & 6 & 0 \\
\hline 25 & Secondary deposition & Poor & Yes & 242 & 24 & 100 & 0 & 53 & 4 & 0 \\
\hline 26 & Residual & Excellent & Yes & 269 & 77 & 100 & 16 & 76 & 76 & 16 \\
\hline 27 & Residual & Very good & Yes & 265 & 46 & 100 & 4 & 64 & 43 & 4 \\
\hline 28 & Residual & Good & Yes & 255 & 28 & 100 & 2 & 58 & 30 & 2 \\
\hline 29 & Residual & Moderate & Yes & 262 & 18 & 100 & 1 & 54 & 22 & 1 \\
\hline 30 & Residual & Poor & Yes & 248 & 12 & 100 & 0 & 53 & 17 & 0 \\
\hline
\end{tabular}

MNI. Bone destruction caused by subsequent burials and by long-term gradual factors such as chemical dissolution and soil pressure create a ceiling upon the number of identifiable skeletons that will be recoverable in a tomb chamber. Simulation shows that a tomb assemblage containing 50 people could equally well represent 50,100 or 1000 original

\section{$\%$ of expected bones present}

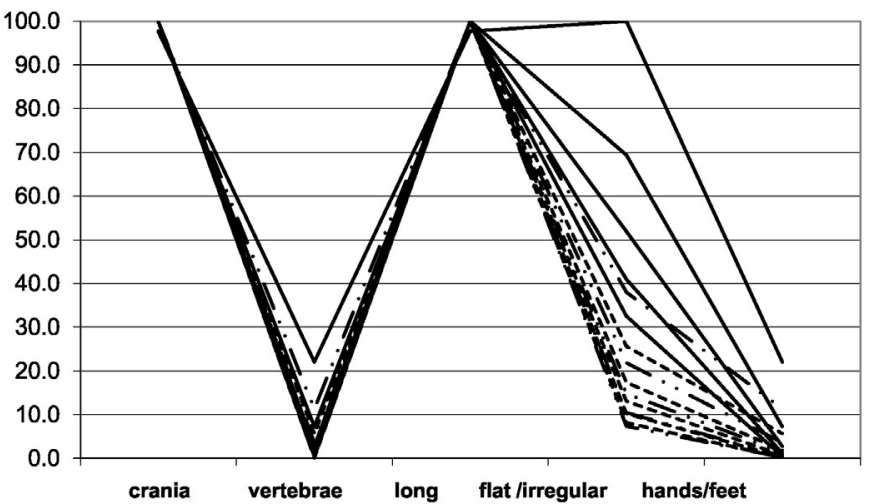

Fig. 6. Simulated element representation in a tomb following secondary deposition (dashed lines), sequential primary deposition (alternating long and short dashes), and residual deposition after removal of some elements (solid lines). Multiple lines of each colour indicate simulation runs with different levels of general bone preservation. depositions. This counter-intuitive conclusion runs directly counter to conventional wisdom formulated through many years' of archaeological experience excavating prehistoric tombs and other commingled assemblages, and it will need to be nuanced with specific arguments reflecting the contextual details of any particular site. For example, an analyst's "feel" for an assemblage may reflect factors such as how many skeletal parts remained in articulation, the ratio of unidentifiable to identifiable fragments, how often bones may be paired or associated as belonging to a single skeleton, and whether different elements yield similar MNEs. At Hazleton North, for example (Saville et al., 1990), few conjoins or paired bones were found, and the assemblage of $9000+$ fragments included many unidentifiable specimens, suggesting potentially a large assemblage in an advanced state of destruction. However, it is important to recognize that, ultimately, we have no direct way of knowing how many bodies were originally deposited in a collective burial; there are no sites with historically known parameters to give us the "right" answer and ground our commonsense assumptions. Even characterizing every bone fragment in an assemblage through aDNA analysis would only tell us about the human remains preserved for study, not about what was originally deposited and no longer present. Hence, we need to take these simulation results seriously as a salutary reminder that there is no simple or linear relationship between the number of bodies deposited and the MNI excavated. At the very least, finding a tomb with a small MNI does not provide evidence of complex ritual programs in which most bodies were deposited elsewhere, or of social hierarchies in which most people were excluded from megalithic burial. 


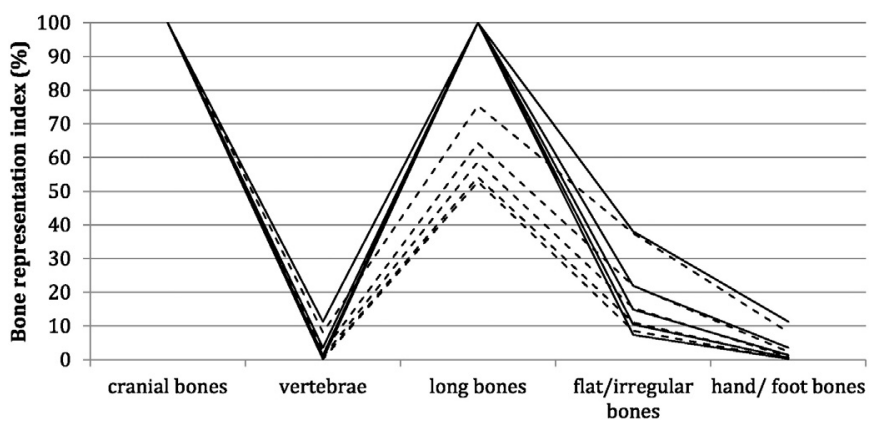

Fig. 7. Simulated element representation in a tomb following sequential primary deposition without (solid lines) and with (dashed lines) preferential treatment of crania. Multiple lines of each pattern indicate simulation runs with different levels of general bone preservation. The diagnostic feature of cranial curation is the ratio between crania and major long bones such as femora.

Secondly, it is common to treat the under-representation of small and fragile bones as a diagnostic marker of secondary deposition. However, as long as processes of bone destruction affect these bones more than larger and more robust bones, this under-representation is part of a common preservational baseline rather than indicating a single burial process. When our assemblage systematically lacks vertebrae, hand and foot bones, or other small and fragile elements, even to a near-total absence of them, this does not mean bodies were first interred elsewhere and then selected elements were re-deposited in the burial space.

Yet, there are some encouraging indicators as to how we can usefully interpret element represent. The first step is to form an idea of a preservational baseline. The Bone Representation Index is useful but also somewhat misleading: it implicitly implies that all elements should be represented equally. Instead, ground conditions and disturbance set a basic preservational pattern of inherently unequal representation. Moreover, even a buried assemblage is a dynamic entity and its proportions may change over the centuries at a rate governed by local conditions. The additional patterns created by human intervention - casual destruction of previous bones, selection and re-deposition of specific elements, etc. - are overlaid on this complex process. Given the complexity of this process, developing alternative formal metrics is probably not the answer. Instead, the best strategy is probably to review element representation curves from as wide a range of sites and funerary processes as possible, to develop a qualitative sense of how they work in general a set of rules of thumb which we can use in appreciating what is typical or unusual about a particular situation. Armed with these, we can then look for informative anomalies which do denote funerary practices. These will be especially obvious when they run counter to expected preservational biases. This article suggests two concrete examples: when the over-abundance of poorly-represented elements suggests a "residual" pattern of deposition, and when an over-abundance of crania compared to major long bones suggests a practice of curation of elements of the cephalic extremity, crania or crania and mandibles. There may well be other informative patterns waiting to be identified.

\section{Acknowledgments}

I am grateful to Christopher Knüsel, Martin Smith and an anonymous reviewer for thoughtful comments which have improved the manuscript substantially.

\section{References}

Bayliss, A., Whittle, A., 2007. Histories of the dead: building chronologies for five southern British long barrows. Camb. Archaeol. J. Spec. Suppl. (Cambridge).

Beckett, J.F., 2005. Death and Burial on the Burren: A Taphonomic Study of three Megalithic Monuments in County Clare, Ireland. Archaeology University of Cambridge, Cambridge.

2pt?>Beckett, J.F., 2011. Interactions with the dead: a Taphonomic analysis of burial practices in three megalithic tombs in county Clare, Ireland. Eur. J. Archaeol. 14, 394-418.

Beckett, J., Robb, J., 2006. Neolithic Burial Taphonomy, Ritual and Interpretation in Britain and Ireland: A Review. In: Gowland, R., Knüsel, C. (Eds.), The Social Archaeology of Funerary Remains. Oxbow, Oxford.

Bello, S., Thomann, A., Signoli, M., Dutour, O., Andrews, P., 2006. Age and sex bias in the reconstruction of past population structures. Am. J. Phys. Anthropol. 129, 24-38.

Binford, L.R., 1980. Willow smoke and dog's tails: hunter-gatherer settlement systems and archaeological site formation. Am. Antiq. 45, 4-20.

Buikstra, J., Ubelaker, D.H., 1994. Standards for Data Collection from Human Skeletal Remains. Arkansas Archaeological Survey, Fayetteville.

Caffell, A, Roberts, C. Janaway, R, Wilson, A, 2001. Pressures on Osteological Collections - The Importance of Damage Limitation. In: Williams, E. (Ed.), Human Remains, Conservation, Retrieval and Analysis: Proceedings of a Conference Held in Williamsburg, VA, 7-11 November 1999British Archaeological Reports. British Archaeological Reports, Oxford, pp. 187-197.

Cox, M., Bell, J., 1999. Recovery of human skeletal elements from a recent UK murder inquiry: preservational signatures. J. Forensic Sci. 44, 945-950.

Dodson, P., Wexlar, D., 1979. Taphonomic investigations of owl pellets. Paleobiology 5, 279-284.

Emberling, G., Robb, J., Speth, J., Wright, H., 2002. Kunji cave: early bronze age burials in Luristan. Iran. Antiq. 37, 47-104.

Knüsel, C., Outram, A., 2004. Fragmentation: the zonation method applied to fragmented human remains from archaeological and forensic contexts. Environ. Archaeol. 9, 85-97.

Malone, C., Stoddart, S., Trump, D., Bonanno, A., Pace, A., 2009. Mortuary Ritual in Prehistoric Malta: The Brochtorff Circle at Xaghra Excavations (1987-1994). McDonald Institute for Archaeological Research, Cambridge.

Mays, S., 1992. Taphonomic factors in a human skeletal assemblage. Circaea 9, 54-58.

Saville, A., Hall, E., Hoyle, J., 1990. Hazleton North: The Excavation of a Neolithic Long Cairn of the Cotswold-Severn Group. English Heritage, London.

Schulting, R.J., Sebire, H., Robb, J.E., 2010. On the road to Paradis: new insights from AMS dates and stable isotopes at Le Dehus, Guernsey, and the Channel Islands middle Neolithic. Oxf. J. Archaeol. 29, 149-173.

Smith, M., Brickley, M., 2009. People of the Long Barrows: Life, Death and Burial in the Earlier Neolithic. The History Press, Stroud.

Ubelaker, D., 1974. Reconstruction of Demographic Profiles from Ossuary Skeletal Samples. Smithsonian, Washington.

Ubelaker, D., 2002. Approaches to Commingling in Human Remains. In: Haglund, W., Sorg, M. (Eds.), Advances in Forensic Taphonomy. CRC Press, Boca Raton, pp. 331-351

Waldron, T., 1987. The Relative Survival of the Human Skeleton: Implications for Palaeopathology. In: Boddington, A., Garland, A., Janaway, R. (Eds.), Death, Decay and Reconstruction: Approaches to Archaeology and Forensic Science. Manchester University Press, Manchester, pp. 149-162. 